\title{
The Community Environmental Monitoring Program: Reducing Public Perception of Risk through Stakeholder Involvement
}

\author{
William T. Hartwell \\ Division of Earth and Ecosystem Sciences, Desert Research Institute, Las Vegas, Nevada \\ Ted.Hartwell@dri.edu
}

\begin{abstract}
The Community Environmental Monitoring Program (CEMP) has promoted stakeholder involvement, awareness, and understanding of radiological surveillance in communities surrounding the Nevada Test Site (NTS) since 1981. It involves stakeholders in the operation, data collection, and dissemination of information obtained from a network of 29 stations across a wide area of Nevada, Utah and California. It is sponsored by the U.S. Department of Energy, National Nuclear Security Administration's Nevada Site Office (NNSA/NSO) and administered by the Desert Research Institute (DRI) of the Nevada System of Higher Education. Integration of a near real-time communications system, a public web site, training workshops for involved stakeholders, and educational programs all help to alleviate public perception of risk of health effects from past activities conducted at the NTS.
\end{abstract}

\section{Introduction}

Between 1951 and 1992, 928 nuclear tests were conducted at the Nevada Test Site (NTS), including 100 atmospheric and 828 underground tests. Initial public reaction to the tests was largely supportive, but by the late 1950s this began to change, largely as a result of fear of the potential for adverse health effects to be caused by exposure to ionizing radiation resulting from the tests. The nuclear power plant accident at Three Mile Island in 1979 served to heighten these fears, as well as foster a general distrust of the federal agencies involved and low public confidence in monitoring results.

Modeled after a similar program that involved the public in monitoring activities around the Three Mile Island nuclear power plant following the accident there in 1979, the Community Environmental Monitoring Program (CEMP) has promoted stakeholder involvement, awareness, and understanding of radiological surveillance in communities surrounding the Nevada Test Site (NTS) since 1981. It involves stakeholders in the operation, data collection, and dissemination of information obtained from a network of 29 stations across a wide area of Nevada, Utah and California (Fig. 1). It is sponsored by the U.S. Department of Energy, National Nuclear Security Administration's Nevada Site Office (NNSA/NSO) and administered by the Desert Research Institute (DRI) of the Nevada System of Higher Education.

Since assuming administration of the program in 2000, DRI has accomplished significant enhancements to the network's data collection and transmission capabilities. A robust datalogging and communications system allows for the near real-time transmission of data to a platform maintained by DRI's Western Regional Climate Center (WRCC), where the data are uploaded and displayed on a publicly accessible web site (http://cemp.dri.edu/). Additionally, the CEMP can serve as part of an emergency response network in the event of an unplanned radiological release from the NTS, and also provides an

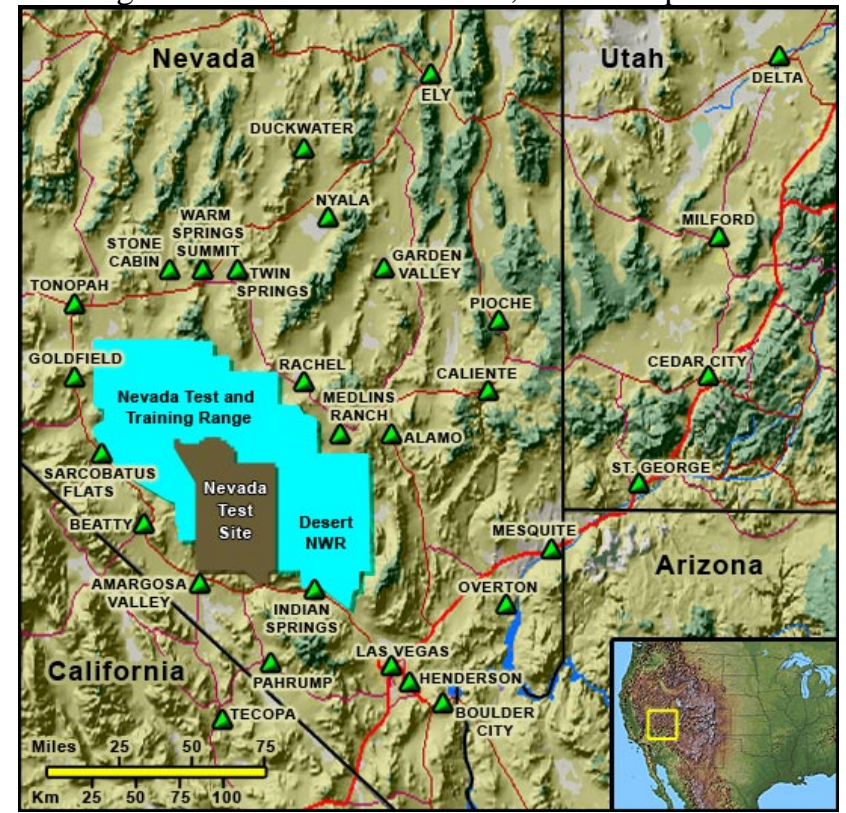

Figure 1. Locations of CEMP network stations. From the CEMP web site home page at http://cemp.dri.edul. 
excellent platform for testing new environmental sensor technologies. Finally, the CEMP provides for training workshops for involved stakeholders, and educational programs which help to alleviate public perception of risk of health effects from past activities conducted at the NTS.

\section{Monitoring Stations}

The CEMP network consists of 29 stations, with 22 in communities and seven at ranch sites. The stations include radiological monitoring devices such as thermoluminescent dosimeters (TLDs) and pressurized ion chambers (PICs) for direct measurement of gamma emitters and high-energy beta particles; and low-volume particulate air samplers for total suspended activity and radioactive particles. The PIC data are recorded in microR per hour, and are displayed in real-time at each of the stations. The air sampler draws approximately 2 to 3 cubic feet of air per minute through a paper filter. Filters are collected weekly and analyzed for gross alpha and beta activity, with a quarterly composite sample analyzed for gamma.

Over the past seven years, DRI has upgraded stations to enhance their technical capability as well as improve their service to the public. Since 2000, the stations have been equipped with a full suite of meteorological equipment to measure air temperature, soil temperature, humidity, wind speed and direction, incident solar radiation, barometric pressure, and precipitation (Fig. 2). The meteorological instruments allow for a better analysis of variations in radiological measurements as a function of weather events. Examples include mini-“fallout" events from precipitation, and changes in natural radon and thoron emissions with barometric changes. Radon and thoron contribute to PIC measurements from the gamma decay of daughter products [1].

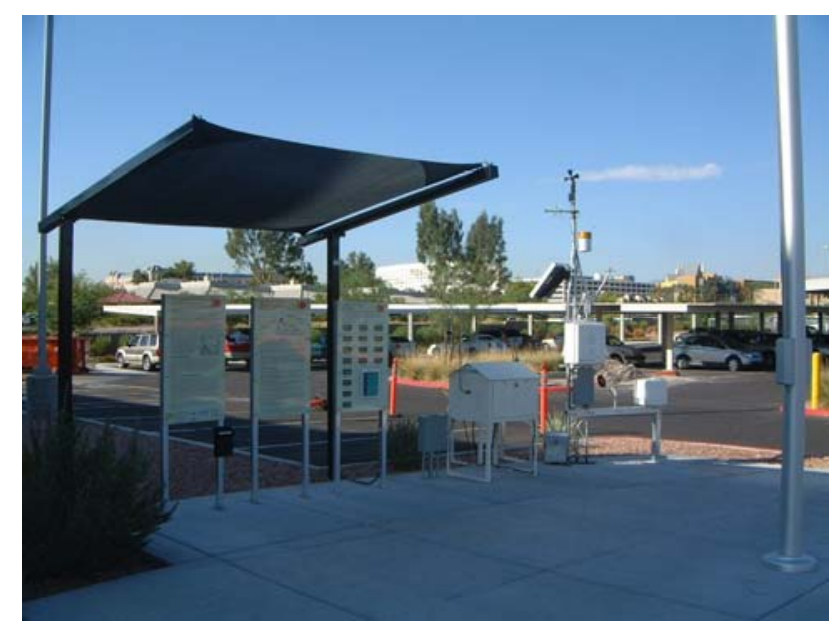

Figure 2. A CEMP station on the campus of the Desert Research Institute in Las Vegas, Nevada.

Power for all instrumentation at the CEMP stations with the exception of the low-volume particulate air samplers is supplied by 50- and 60-watt solar panels operating in conjunction with a deep-cell battery, with trickle chargers at five locations. Air samplers are powered off local electrical grids.

\section{Dataloggers and Communications}

During 2005 through early 2007, DRI transitioned to CR1000 dataloggers. Added benefits include increased memory, additional measurement channels, and the ability to easily switch between different communications modes. This has enabled CEMP stations to have the potential for multiple means of communicating data, providing backup data acquisition capabilities in the event of a communications system outage.

The majority of the stations are now able to relay their data via DSL and wireless internet connections, with the remainder operating on landline, cellular phone, and satellite, in the case of the remote ranch sites. This coupling of state-of-the-art dataloggers and two-way communications systems (with the exception of the ranch sites) allows for near real-time data acquisition by the Western Regional Climate Center (WRCC) in Reno, which is managed by DRI for the National Oceanic and Atmospheric Administration (NOAA). Data for most stations are acquired as frequently as every 10 minutes.

\section{CEMP Web Site}

One of the most important additions to the CEMP over the past decade has been the development and implementation of a public web site (http://cemp.dri.edu/). A primary mission of the CEMP is to provide for public transparency and accessibility to collected data. Prior to implementation of the web site in 
2000 , access to data was restricted to viewing the realtime display located at each station site, observing a summary of the previous month's data posted on a bulletin board at the station site, or waiting for the publication of the annual data summary in the yearly Nevada Test Site Environmental Report (NTSER) [2]. Following recent upgrades of station communications and dataloggers, the WRCC is able to receive and post collected data to the web site as often as every 10 minutes for stations with direct internet service, and at least every three hours for remote stations located at ranch sites with satellite communications. With the implementation of the CEMP web site, the public has access to near real-time monitoring data. The site also provides a means to access and display station data in both tabular and graphical outputs for current and archived data for individual or multiple stations (Fig. 3).

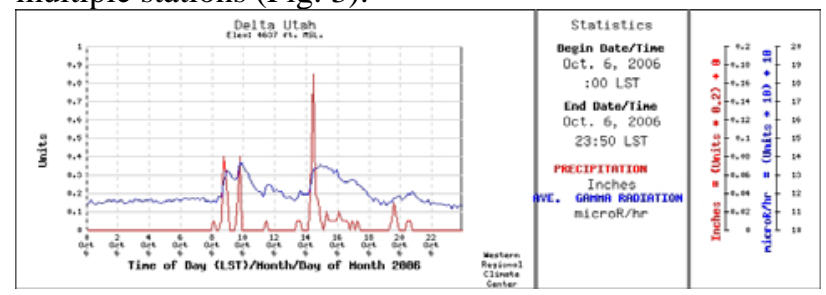

Figure 3. An example of one type of graphical output generated by the CEMP web site. This figure shows the relationship between precipitation events and background gamma readings during a 24-hour period at the Delta, Utah, station.

In addition to providing data associated with the CEMP, the WRCC provides climate data for 12 western states, including Alaska and Hawaii, which can be accessed via a link on the CEMP web site. The web site also provides an ideal interface for monitoring the status of station sensors and allowing for remote troubleshooting of power or instrumentation issues. This has resulted in significant cost savings to the program. The web site provides methods for querying and displaying data that have become increasingly sophisticated as the site has evolved, and there are now a multitude of options that will satisfy both the casual and professional user. Examples of available features include: educational information links to numerous sources on the nature of ionizing radiation, sources of both natural and man-made radioactivity, and what is known about potential health effects; the ability to generate trending graphs and tables; the ability to generate wind rose diagrams; and links to information and presentations from past annual CEMP workshops. Finally, all of these features combine with the communications and data collection technologies to provide a platform that is ideal for field-testing prototype environmental sensors.

\section{The CEMP and Public Communication}

While the development of a public web site has been very important in increasing transparency and accessibility to the monitoring data, public involvement in the CEMP goes far beyond simple accessibility to the data. DRI employs local citizens, most of them high school science teachers, whose responsibilities include ensuring that the equipment is operating normally and collecting air filters and routing them to DRI for laboratory analysis [3]. These Community Environmental Monitors (CEMs) are available to discuss the monitoring results with the public, to participate in formal presentations to community and school groups, and in general serve as a focal point for DRI and NNSA/NSO for identifying environmental concerns in their communities. CEMs also participate in annual workshops organized by DRI and NNSA/NSO (Fig. 4). The workshops enable them to participate more fully in public education forums, and to better answer questions from the local communities about the monitoring program and data results in their area and throughout the network. Workshops include presentations on the "ABC's of Radiation," hands-on exercises targeting equipment maintenance and minor troubleshooting issues, and a valuable exchange of ideas, concerns, and suggestions among all the program participants.

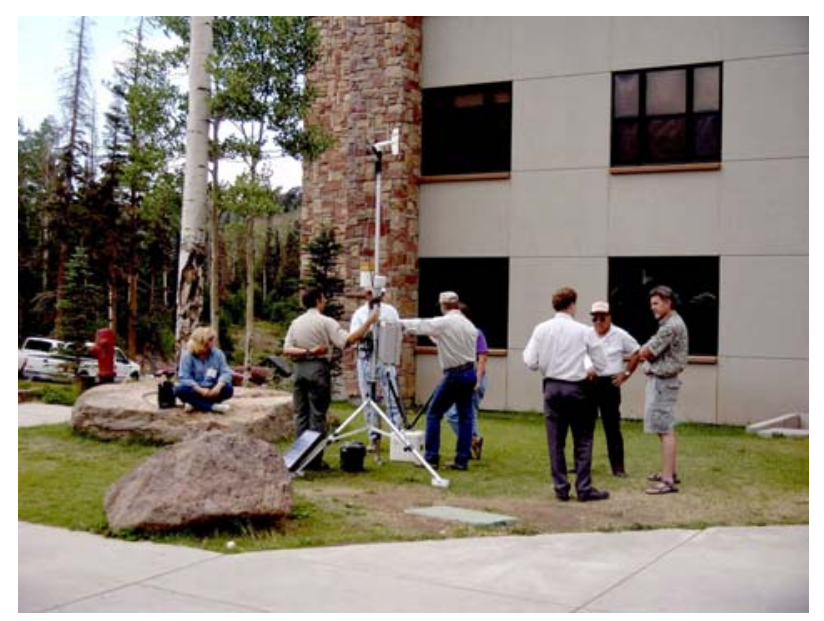

Figure 4. Community members receive training on the operation of a mobile CEMP station at an annual workshop in Brian Head, Utah.

Presentations by NNSA/NSO and other DOE personnel regarding issues of concern to local communities (e.g., the planned repository at Yucca Mountain, Nevada, radioactive waste transportation, water testing, etc.) are also an important component of the workshops. The CEMs are trained to understand the results of the environmental monitoring, and become 
knowledgeable spokespersons on subjects ranging from radiation detection to local environmental conditions. Since many CEMs are high school science teachers, they are encouraged to use knowledge gained from these workshops and incorporate it into their classroom curricula, providing an educational forum for students to discuss radiological issues that might otherwise be poorly understood or neglected.

While CEMs are the primary means of interacting with and disseminating information to the public, DRI and NNSA/NSO personnel participate in various community events, producing displays discussing the program for county fairs and sometimes attending NTS Community Advisory Board meetings held in rural communities. DRI also annually conducts a number of community outreach presentations on the CEMP and related issues that range from one hour to a full day in length. Data collected from the CEMP stations are summarized annually for inclusion in the NTSER, which is distributed to all the CEMs and the participating communities.

Participation of community members in the data gathering and reporting process can often defuse tensions and allay public concern regarding the credibility of the reported data. Additionally, the costs of long-term monitoring can actually be significantly reduced by employing willing members of stakeholder communities to assist in conducting essential nontechnical activities.

Entrusting local stakeholders with monitoring responsibilities helps build a positive rapport with the participating communities. In addition, CEMP field technicians are encouraged to spend time interacting with the local populace and to participate in the local economies through program equipment and supply purchases when practicable. These activities help to ensure an increased public visibility and overall positive impression of the program.

\section{Conclusions}

The CEMP employs an approach that integrates stateof-the-art data collection and transmission, the internet, and public participation. The CEMP can serve as a model for engaging the public in environmental monitoring in way that is beneficial to all involved parties. Radiological and other environmental monitoring results reported by federal agencies and their contractors are often regarded with distrust and suspicion by the general public. The CEMP helps to alleviate this climate of distrust through direct involvement by stakeholders and by providing transparency and rapid access to collected monitoring data.

\section{Acknowledgements}

Work cited in this article was accomplished under DOE contracts DE-AC52-00NV13609 and DE-AC5206NA26383. The authors would like to gratefully acknowledge the participation and contributions of all the stakeholders who have made the CEMP a success over the years, some of whom have been with the program since its inception 26 years ago. We would also like to thank all the various agency personnel at DRI, NNSA, and EPA who have supported the CEMP with their time, ideas, and enthusiasm.

\section{References}

[1] M. Eisenbud and T. Gesell. Environmental Radioactivity. Academic Press, New York, 1997, 656pp.

[2] C.A. Wills and A.L. McCurdy, Nevada Test Site Environmental Report 2005, prepared by National Security Technologies for the U.S. Department of Energy, National Nuclear Security Administration, Nevada Site Office DOE/NV/25946-007, 2006.

[3] W.T. Hartwell, J. Tappen, and L. Karr, "Positive Community Relations: the Keystone to the CEMP,” Poster presented at the WM'06 Conference, Tucson, Arizona, 2006. 